\title{
Evaluation of detachable Ga based solder contacts for thermoelectric materials
}

\author{
H. Kolb ${ }^{1, *}$, R. Sottong ${ }^{1}$, T. Dasgupta ${ }^{2}$, E. Mueller ${ }^{1,3}$ and J. de Boor ${ }^{1}$ \\ ${ }^{1}$ Institute of Materials Research, German Aerospace Center (DLR), , D-51147 Cologne, Germany \\ ${ }^{2}$ Dept. of Metallurgical Engineering and Materials Science, Indian Institute of Technology Bombay, Mumbai 400076, India \\ ${ }^{3}$ Institute of Inorganic and Analytical Chemistry, Justus Liebig University Giessen, Heinrich-Buff-Ring 17, D-35392 Giessen, \\ Germany \\ "Hendrik.Kolb@dlr.de
}

Low electrical and thermal contact resistances are a prerequisite for highly efficient thermoelectric generators. Likewise, certain measurement setups for the characterization of thermoelectric materials rely on good quality of the contacts between sample and setup. Detachable contacts are an interesting alternative to permanent contacting solutions due to ease of handling and non-destructive disassembly of valuable samples. Therefore, the applicability of a gallium based liquid metal solder as detachable contact material was studied, particularly with regard to the compatibility of the solder with the state of the art thermoelectric materials $\mathrm{CoSb}_{3}, \mathrm{Mg}_{2} \mathrm{Si}_{1}, \mathrm{FeSi}_{2}$. Tungsten, nickel, chromium and titanium were tested as protective coatings between the thermoelectric materials and the liquid metal solder. Electrical measurements show that some materials form excellent and stable contacts with the solder for a limited temperature range. At higher temperatures, application of a protection layer is found to be necessary for all materials under investigation. Tungsten and nickel show promising results as protection layer.

\section{Introduction}

An increasing demand for energy contrasted by limited resources of fossil fuels results in focused research for new energy sources and the improvement of current technologies. The approach to convert waste heat into electrical energy by thermoelectric devices is one opportunity to increase the efficiency of any process where waste heat is released. Thus, highly efficient thermoelectric generators are required. Along with the thermoelectric properties of the semiconductor couples inside the module, contact resistances are a key parameter for the efficient function ${ }^{1-5}$. High electrical or thermal contact resistances will strongly deteriorate the efficiency of thermoelectric modules ${ }^{6}$. Furthermore, contact resistances can cause considerable measurement uncertainty in electrical and thermal material characterization, resulting in less trustworthy data and misinterpretations ${ }^{7}$. 
It was found that very good electrical and thermal contact of the measuring probes is a primary requirement for reliable Seebeck coefficient measurement ${ }^{8}$. One relevant effect of the thermal contact resistance is the generation of a temperature drop across interfaces due to the residual heat flow along probe wires ${ }^{9,10}$. Poor contacts at electrical or thermal facial connections can interfere with the homogeneity of the electrical and thermal heat fluxes, thus making applied simple one-dimensional evaluation models inaccurate or invalid ${ }^{11}$.

This article focuses on the development of detachable contacts for thermoelectric materials using a galliumbased liquid metal solder. Liquid metals have a high electrical and thermal conductivity and are therefore of great interest for various applications in research, engineering, or medicine, i.e. for cooling systems ${ }^{12,13}$, microelectromechanical systems ${ }^{14}$ or as electrode materials ${ }^{15,16}$. Especially Ga-In-Sn alloys are attractive due to their non-toxicity, the melting point below room temperature and the chemical compatibility with most metals at ambient temperature ${ }^{17,18}$. Nevertheless, due to the special chemical properties of gallium, it has a high affinity to react with many metals at higher temperatures $14,19,20$.

Detachable contacts can be highly advantageous compared to durable ones because of the simpler assembly of a (force-fit) module or a simpler installation in a measurement setup. Also samples, parts of the measurement system or parts of a module can be reused after an experiment and additionally adjustments can be carried out respectively without any damage. No matter whether the contacts are solid or liquid, the long-term stability of the interface of the contact material and the thermoelectric material is always important. For solid contacts the soldering process can have a negative influence on the sample properties due to the related heat treatment. For high temperature applications a solder with a higher melting point than the maximum application temperature of the device has to be chosen. This heat treatment can possibly cause a change of the thermoelectric or mechanical properties of the sample.

First, we give a short description of the measurement setup we use for the characterization of thermoelectric materials. In this setup, a liquid metal solder for the contacting of a sample to the sample holder is used to achieve low electrical and thermal contact resistances. The performed measurements on state of the art thermoelectric materials demonstrate that a protective coating is necessary for measurements at higher temperatures due to a reaction of the soldering material with the samples. Such a reaction can cause high contact resistance at the interface resulting in a strongly decreased apparent value of the electrical conductivity upon measurement. 
We performed annealing experiments of potential coating materials brought into contact with the solder to investigate their long term stability. Subsequently, the samples were analyzed using scanning electron microscopy (SEM) and energy dispersive X-ray spectroscopy (EDX).

Finally, several protective coatings were applied to the thermoelectric materials by electroplating, physical vapor deposition or a direct sintering method and characterized by electrical conductivity measurements and SEM analyses. Different methods are presented to demonstrate that there are several possibilities to develop a protective coating. In the following, all interface metallic layers are referred to as coating independent of the coating method since the function of these layers is in all cases to protect the sample from a reaction with the solder.

\section{Experimental set-up}

The employed configuration for the electrical conductivity measurement is shown in Figure 1. Two identical chromium-plated copper blocks, each equipped with a thermocouple and a resistive heater, are the main parts of the sample holder. A sample is placed between the two end faces of the blocks and contacted with the galliumbased liquid metal solder Galinstan ${ }^{1}{ }^{1}$ (Gallium 68-69 wt.-\%; Indium 21-22 wt.-\%; Tin 9.5-10.5 wt. - \%). The solder is in the liquid phase at room temperature and can be applied to the surface of the sample and the blocks by brush. It sticks to the surfaces due to its high adhesion and the contact layer has a thickness of about $0.5 \mathrm{~mm}$ before the sample is attached to the sample holder. A combined thermoelectric measurements system (CTEM) ${ }^{21}$ is used for the following experiments.

\footnotetext{
${ }^{1}$ Geratherm MEDICAL AG
} 


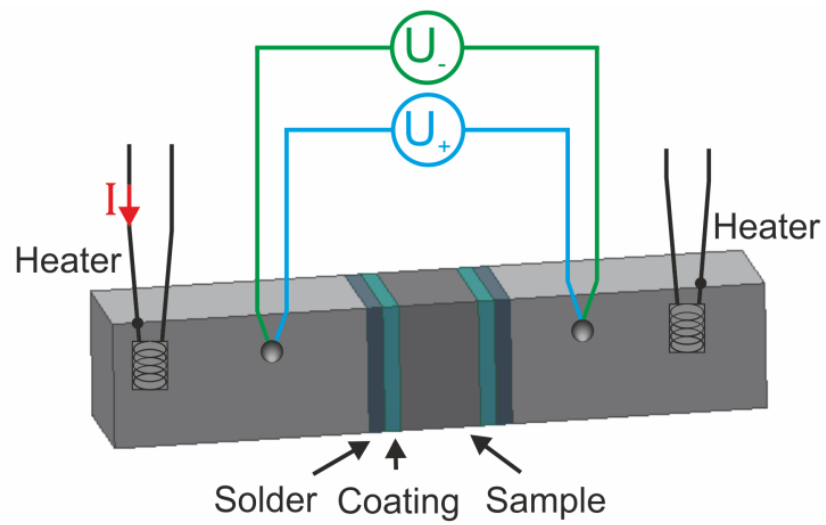

Figure 1: Sketch of the sample mounting in the sample holder. A liquid metal solder is used to provide contact between the sample and the two chromium-plated copper blocks. For electrical and temperature measurements a thermocouple is placed in a small hole in each of the blocks. Resistive heaters are embedded in a further hole of each block.

Electrical conductivity measurements can be used to evaluate contact quality roughly, as electrical properties are quite susceptible to contact quality in this arrangement. In the setup, the electrical conductivity is determined by leading an AC current via the blocks through the sample holder and measuring the ohmic voltage drop over the sample by one of the thermocouple legs, denoted by $U_{+}$or $U_{-}$in Figure 1. A comparison of the measured electrical conductivity to a reference value leads to an estimate of the ratio of the contact resistance to the sample resistance. In case of significantly high electrical contact resistance, the measured electrical conductivity in the CTEM is smaller than the reference value, because the measured resistance $R=2 R_{c}+R_{\mathrm{S}}$ contains the sample resistance $R_{S}$ and twice the contact resistance $R_{c}$. The formation of an insulation layer or a low wetting of the block - sample surfaces by the solder can cause high contact resistances.

Material synthesis and sample fabrication details are given in literature for $\mathrm{CoSb}_{3}{ }^{22}$, for $\mathrm{Mg}_{2} \mathrm{Si}^{23}$ and for $\mathrm{FeSi}_{2}{ }^{24}$, respectively. Reference data was obtained using a setup for high temperature Seebeck coefficient and electrical conductivity measurements ${ }^{25}$. $\mathrm{CoSb}_{3}$ samples were coated by physical vapor deposition, $\mathrm{FeSi}_{2}$ by electroplating and $\mathrm{Mg}_{2} \mathrm{Si}$ by a direct sintering method ${ }^{26}$. Typical layer thickness for sputtering amounts to a few micrometers, for electroplating up to $10 \mu \mathrm{m}$ and for the direct sintering method to about $100 \mu \mathrm{m}$.

\section{Results}

Figure 2 shows the results for thermoelectric materials under investigation measured soldered with the Ga-In-Sn solder. Drastic changes with temperature and deviations from the reference data are hints for poor electrical contact between sample and measurement system. 
The measurement starts at room temperature, followed by a heating sweep (full circles) and continues with a cooling sweep (open circles) after the maximum temperature was reached. All measurements were performed under vacuum conditions with a pressure $p<10^{-1} \mathrm{~Pa}$. Diagram (a) in Figure 2 shows that the room temperature value for $\mathrm{FeSi}_{2}$ at the beginning of the measurement fits well to the reference (deviation < 5\%). Between $350 \mathrm{~K}$ and $400 \mathrm{~K}$ there is a strong drop in the electrical conductivity resulting by an increase in contact resistance which is saturating at $550 \mathrm{~K}$. The cooling behavior shows a weaker temperature dependence than the reference measurement which means that the behavior is dominated by high contact resistances. In diagram (b) a similar behavior can be seen for $\mathrm{CoSb}_{3}$, starting with a good fit to the reference measurement up to $550 \mathrm{~K}$ (deviation < $2 \%$ ) and ending with a strong drop due to an increase in electrical contact resistance. For $\mathrm{Mg}_{2} \mathrm{Si}$ (c), the measurement looks different. The starting value at room temperature differs from the reference value, indicating that a highly resistive layer forms between $\mathrm{Mg}_{2} \mathrm{Si}$ and the solder even at room temperature. The high tendency of $\mathrm{Mg}_{2} \mathrm{Si}$ to oxidize was already observed in a study on barrier layer materials for $\mathrm{Mg}_{2} \mathrm{Si} / \mathrm{Ni}$ interfaces ${ }^{27}$. It is described in this study that magnesium oxide forms on the surface leading to a decreasing wettability by an InGa solder, which has comparable properties to the Ga-In-Sn solder employed in our study. 

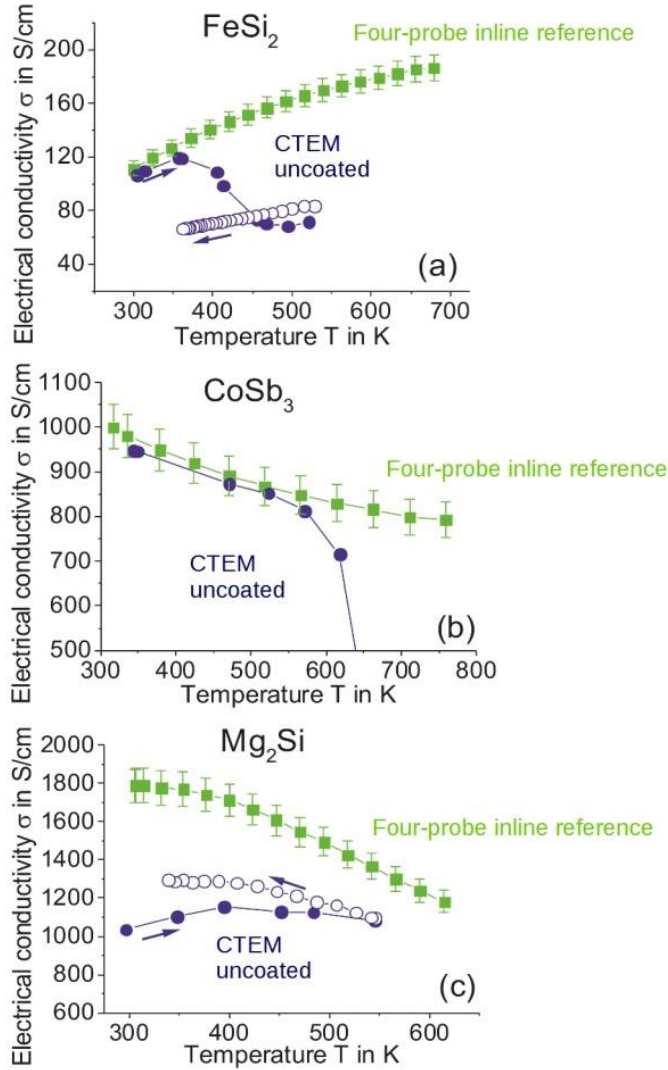

Figure 2: Apparent electrical conductivity of $\mathrm{FeSi}_{2}$ (a), $\mathrm{CoSb3}$ (b) and $\mathrm{Mg}_{2} \mathrm{Si}$ (c) measured in the CTEM without protective coating on the sample surfaces. Gallium/indium/tin was used as a liquid metal solder. Solid symbols are used for the heating and unfilled symbols for the cooling branch of the measurements. All reference data was measured with a system which does not require a contact development due to the use of pressure contacts in a four-probe inline measurement set-up ${ }^{25}$.

The results in Figure 2 show that a protection layer is necessary for high temperature measurements to separate the sample material from the solder and effectively prevent a reaction between both. Potential metal coating candidates are titanium, nickel, tungsten and chromium. Titanium proved its suitability as a protective coating for $\mathrm{CoSb}_{3}$ to prevent the sublimation of antimony under temperature treatment ${ }^{28}$. Nickel and tungsten have been reported to protect incompatible materials from the solder ${ }^{17}$. Also, chromium was tested as it is often used as a protective layer for various metals. To check whether the coating material does react with the solder at higher temperatures, bulk samples of the pure coating materials were annealed in direct contact with the solder in a vacuum oven for $24 \mathrm{~h}$ at $773 \mathrm{~K}$.

SEM micrographs and elemental compositions from EDX analyses of the samples after the heat treatment are presented in Figure 3 and Table I. 


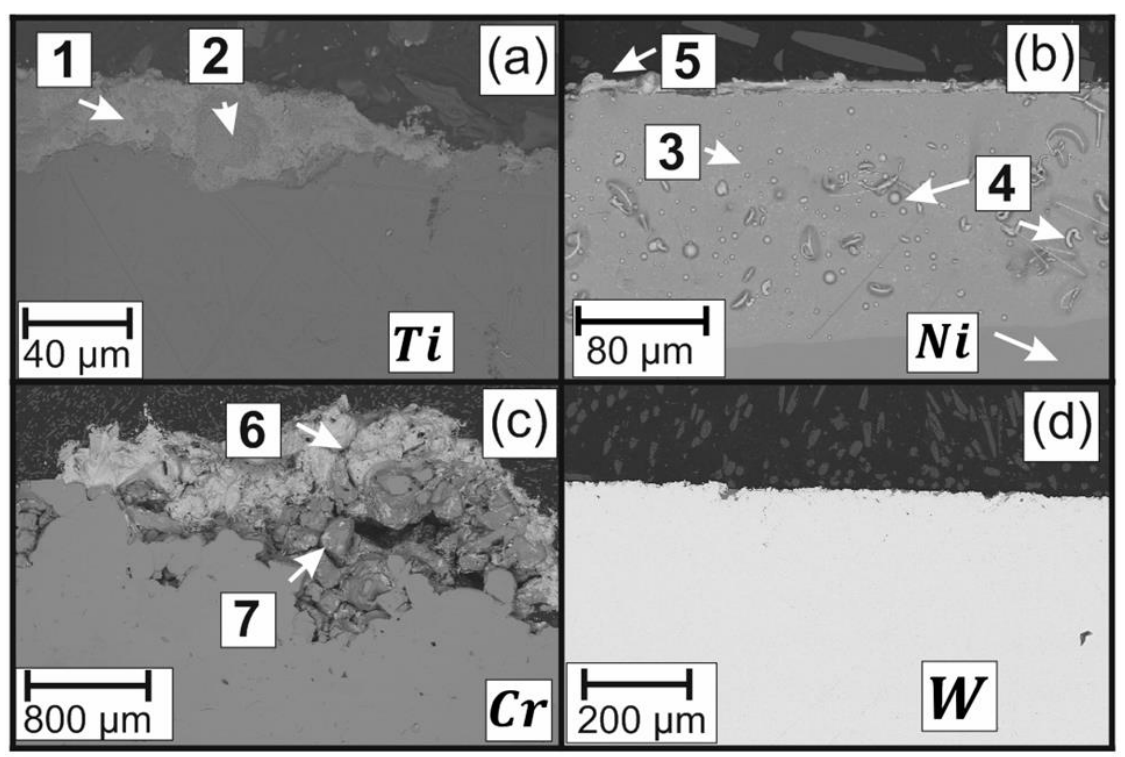

Figure 3: SEM images of bulk samples of the pure coating materials after a temperature treatment of $773 \mathrm{~K}$ for $24 \mathrm{~h}$ in a vacuum oven and in direct contact with the solder. The samples have been cleaned with ethanol before the SEM investigations to remove the liquid solder remains. Titanium is shown in (a), nickel in (b), chromium in (c) and tungsten in (d). A formation of different phases can be observed on the surface of all materials except for tungsten. The composition of the phases is shown in Table I. A two-phase system forms with $\mathrm{Ti}$, a homogeneous layer with small inclusions with $\mathrm{Ni}$ and a crumbly structure with $\mathrm{Cr}$. No reaction layer can be found for tungsten. The thickness of the reaction layers on the bulk samples of the coating materials and the solder vary strongly due to differences in their reactivity and corrosion rates.

For titanium, it was observed that the color of the sample and the solder changed into red during the experiment. The SEM pictures showed areas on the sample edge where a compound different from pure titanium is found. Two phases can be distinguished in the reaction area, visible in the SEM picture as brighter marked as (1) and darker areas as (2), the composition from EDX analyses is given in Table I.

The solder, which was in contact with the nickel sample, strongly decreased in volume during the experiment indicating that the solder diffused into the sample. Accordingly, Figure 3 (b) shows that an almost $200 \mu \mathrm{m}$ thick reaction layer (3) formed containing small inclusions (4). The thin layer on the surface of the sample (5) consists of In and Sn and only a very small amount of Ga.

For chromium, a crumbly layer at the sample surface formed. The composition of the reaction areas is not uniform. All three elements of the solder and also chromium can be found in all reaction areas. The main difference between the brighter (6) and the darker phases (7) is the gallium to chromium ratio. Darker areas, which are generally farther away from the sample surface, have a higher chromium fraction. The crumbly structure indicates that the chromium dissolved into the solder. 
For tungsten, no reaction layer was found, which means that it remains as a candidate for protective coatings in the temperature range up to $773 \mathrm{~K}$.

\begin{tabular}{|c|l|}
\hline & Composition in atomic \% \\
\hline Figure 3 (a): (1) & Ga 75, Ti 25 \\
\hline Figure 3 (a): (2) & Ga 72, In 12, Ti 9, Sn 7 \\
\hline Figure 3 (b): (3) & Ga 65, Ni 35 \\
\hline Figure 3 (b): (4) & In 50, Ga 25, Sn 20, Ni 5 \\
\hline Figure 3 (b): (5) & In 55, Sn 41, Ga 4 \\
\hline Figure 3 (c): (6) & Ga 70, In 13, Cr 9, Sn 8 \\
\hline Figure 3 (c): (7) & Cr 84, Ga 12, In 3, Sn 1 \\
\hline
\end{tabular}

Table I: Results in atomic \% from EDX analyses of the phases in Figure 3. The statistical error for an EDX analysis on a polished bulk sample is $\pm 5 \%{ }^{29}$.

Although $\mathrm{Ni}$ reacts with the solder, it can be used as a protection layer for $\mathrm{FeSi}_{2}$ and $\mathrm{Mg}_{2} \mathrm{Si}$ for a limited temperature range or a limited period of time, see Figure 4. The applied coating methods and the resulting layer thicknesses are summarized in Table II.

\begin{tabular}{|l|l|l|l|c|}
\hline \multicolumn{1}{|c|}{$\begin{array}{c}\text { Substrate + } \\
\text { Coating }\end{array}$} & \multicolumn{1}{|c|}{ Method } & \multicolumn{1}{|c|}{ Medium } & $\begin{array}{c}\text { Layer } \\
\text { thickness }\end{array}$ & Reference \\
\hline $\mathrm{CoSb}_{3}+\mathrm{W}$ & $\mathrm{DC}$ sputtering & $\mathrm{Ar}$ & $2 \mu \mathrm{m}$ & - \\
\hline $\mathrm{CoSb}_{3}+\mathrm{Ti}-\mathrm{W}$ & $\mathrm{DC}$ sputtering & $\mathrm{Ar}$ & $\begin{array}{l}1 \mu \mathrm{m} \mathrm{Ti}+ \\
1 \mu \mathrm{m} \mathrm{W}\end{array}$ & 4 \\
\hline $\mathrm{FeSi}_{2}+\mathrm{Ni}$ & Electro- & $\mathrm{NiSO}_{4}\left(\mathrm{H}_{2} \mathrm{O}\right)_{6}$ & $5 \mu \mathrm{m}$ & 30 \\
& chemical plating & & & \\
\hline $\mathrm{Mg} 2 \mathrm{Si}+\mathrm{Ni}$ & Sintering & Vacuum & $100 \mu \mathrm{m}$ & 26 \\
\hline
\end{tabular}

Table II: Overview of the applied coating methods. Since tungsten shows no reactivity with the Ga-In-Sn solder it was chosen as a coating material for $\mathrm{CoSb}_{3}$. Titanium is known from literature ${ }^{4}$ to be a possible interlayer to solve a mismatch in the coefficients of thermal expansion between the substrate and the coating. Nickel is known from literature to be a candidate for a contact material for $\mathrm{FeSi}_{2}{ }^{30}$ and $\mathrm{Mg}_{2} \mathrm{Si}^{26}$. 


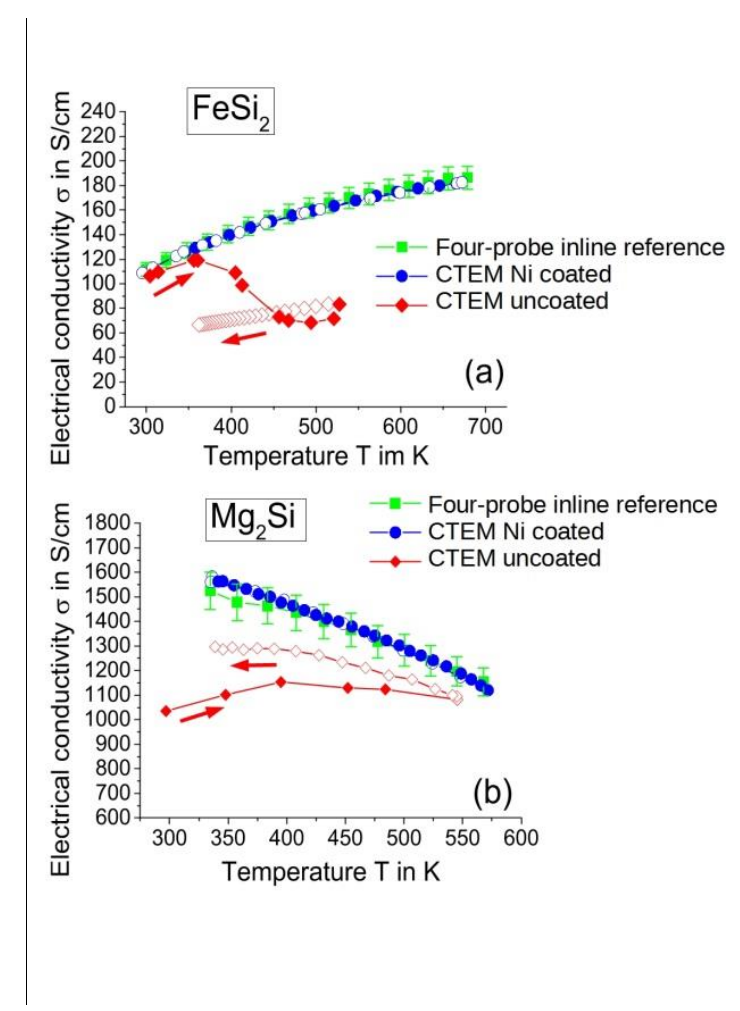

Figure 4: Electrical conductivity measured on thermoelectric samples with protective Ni coating compared to uncoated samples. (a) $\mathrm{FeSi}_{2}$ coated by electroplating, (b) $\mathrm{Mg}_{2} \mathrm{Si}$ bonded by direct sintering. The four-probe inline reference data were obtained by a system for high temperature measurement of Seebeck-coefficient and electrical conductivity ${ }^{25}$. Solid symbols show the first branch of the measurement when the samples are heated up from point to point, unfilled symbols indicate the following cooling-down branch.

The results show that although $\mathrm{Ni}$ forms a reaction layer, which has no detrimental influence on the electrical conductivity measurement results. It was not possible to go to higher temperatures since the results of Figure 3 showed that chromium, which is the protective coating on the blocks of the sample holder, is not a stable protective coating at higher temperatures. For further investigations on the high temperature behavior of $\mathrm{Ni}$, the coating of the sample holder blocks has to be changed.

Heating-up and cooling-down branches fit perfectly together for both nickel coated materials, consequently, there is no significant change in contact resistance over one measurement cycle. The good accordance to the reference (deviations $<3 \%$ for $\mathrm{FeSi}_{2}$ and $<5 \%$ for $\mathrm{Mg}_{2} \mathrm{Si}$ ) implies that contact resistance is low. Attempts to find protective coatings for $\mathrm{CoSb}_{3}$ were not yet successful. In none of the experiments any reaction between the coating and the sample or between the coating and the solder were observed, but high contact resistance was always found. The SEM pictures in Figure 5 show that the coating layers are close and homogeneous, but do not show good adhesion to the sample. A crack between the protective coating and the sample leads to high contact resistance. A possible reason for this is a mismatch of the thermal expansion coefficient of $\operatorname{CoSb}_{3}\left(13.5 \times 10^{-6} \mathrm{~K}^{-1}\right)$ ${ }^{31}$ and tungsten $\left(4.3 \times 10^{-6} \mathrm{~K}^{-1}\right)^{32}$. Due to this difference, the layer can delaminate from the sample as a result of 
high shear stress. The attempt with a double-layer coating by adding titanium as an interlayer ${ }^{4}$ between tungsten and $\mathrm{CoSb}_{3}$ was not successful, either.

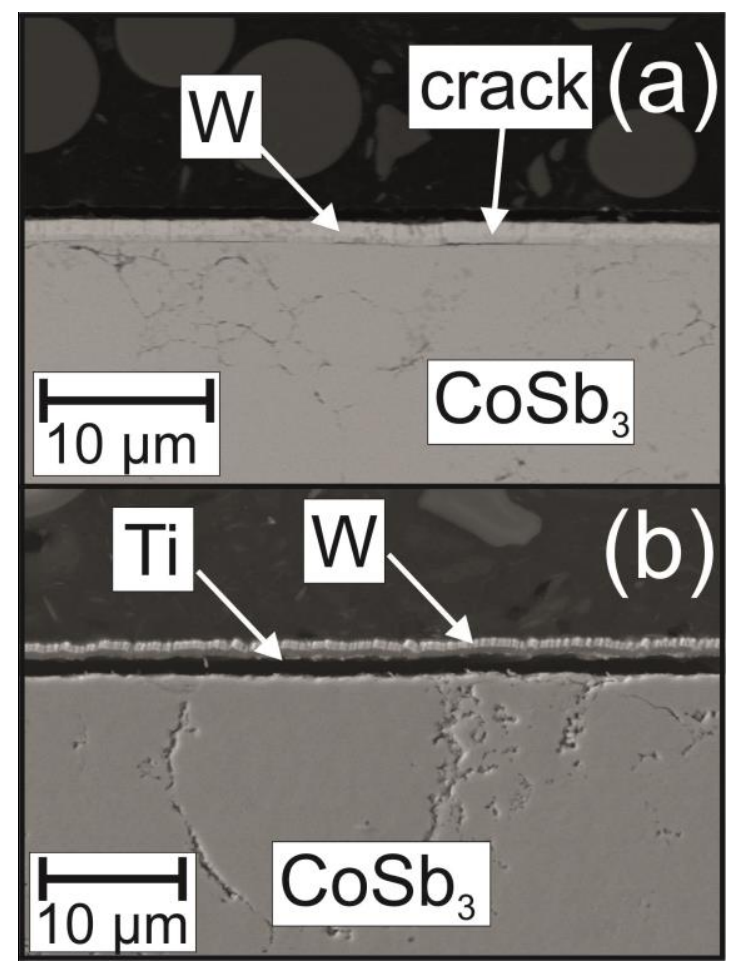

Figure 5: $\mathrm{CoSb}_{3}$ sample with tungsten coating (a) and with double layer titanium/tungsten coating (b).

\section{Discussion}

These experiments lead to the conclusion that of the investigated materials only tungsten is an effective protection layer material for long-term applications. The results for the reactivity of tungsten are in accordance with the findings for pure gallium and tungsten ${ }^{14,20,33}$, where a high corrosion resistance and no reaction up to $1073 \mathrm{~K}$ are reported.

Titanium strongly tends to react with the solder: we observe the formation of a reaction layer as well as a change of the solder. A dissolution of titanium at $723 \mathrm{~K}$ and a formation of $\mathrm{GaTi}_{3}(32,6 \mathrm{wt} . \% \mathrm{Ga})$ an $\mathrm{GaTi}_{2}(42,1$ wt.\% $\mathrm{Ga}$ ) at a temperature of $843-893 \mathrm{~K}$ was also found in literature ${ }^{14,34}$, and is according to the phase diagram ${ }^{35,36}$.

However, on smaller time scales that are i.e. sufficient for material or module characterization (max $24 \mathrm{~h}$ for complete characterization in the CTEM), also chromium and nickel can effectively protect samples from a reaction with the solder. Nickel is effective and does not influence the measurement, because the reaction layer has metallic properties. It has a much higher electrical conductivity than a typical thermoelectric semiconducting sample. Therefore, the influence on the measured electrical conductivity is negligible. The crumbly reaction 
layer forming at the surface of chromium will cause an increase in contact resistance due to its porous structure. Nevertheless, the reaction is slow and the sample is only exposed for a short time to high temperatures (complete measurement less than $24 \mathrm{~h}$ ). Our results indicate that the reaction is not progressing so far that it disturbs the measurement

The SEM and EDX analyses in Figure 3 and Table I, showing the reactivity of the coating materials with Ga-InSn, are in good agreement with the results found for the compatibility of gallium with metals ${ }^{14}$. Chromium and gallium form an irregular corrosion layer after a heat treatment of $49 \mathrm{~h}$ at $673 \mathrm{~K}^{19}$, the corrosion rate was found to be $0.04 \mathrm{~mm} /$ day. Furthermore, they determined by the same experiment for nickel a corrosion rate of 0.21 $\mathrm{mm} /$ day and the formation of a reaction layer mainly consisting of $\mathrm{Ni}_{2} \mathrm{Ga}_{3}$. The rate for nickel is in good agreement with the rate we found in our experiment, see Figure 3, and also in good agreement with the high solubility of nickel and liquid gallium with $0.11 \mathrm{wt} . \% /$ day at $673 \mathrm{~K}^{20}$. For chromium, the corrosion rate in our experiment was much higher due to the by $100 \mathrm{~K}$ higher temperature during the heat treatment.

Without coating, it is possible to keep $\mathrm{CoSb}_{3}$ in contact with Ga-In-Sn up to $550 \mathrm{~K}$ without impacting the measurement due to a change in contact resistance. Nickel is not suitable as a coating material for skutterudites due to its high difference in the coefficient of thermal expansion and the partial substitution of Co sites by $\mathrm{Ni}$ at high temperatures ${ }^{4}$, which can cause a change of the thermoelectric properties of the sample. Poor adhesion of the coating to the sample and big differences in the thermal expansion coefficient prevented a successful coating on $\mathrm{CoSb}_{3}$ using tungsten. Titanium is described as a possible coating for $\mathrm{CoSb}_{3}$ skutterudites ${ }^{28}$, but it reacts with the solder at $723 \mathrm{~K}$. Therefore, titanium is a possible candidate as an interlayer material for multiple layer coatings to improve adhesion or reduce the mismatch of the coefficient of thermal expansion at the interfaces ${ }^{4}$.

The studied silicides $\mathrm{FeSi}_{2}$ and $\mathrm{Mg}_{2} \mathrm{Si}$, when uncoated, tend to react with the solder even at temperatures little above room temperature. Although a reaction layer of gallium and nickel forms, nickel can be used as a protective coating for the characterization of materials in a measurement due to the short time the sample is exposed to higher temperatures (typical measurement duration less than $24 \mathrm{~h}$ ). Successful measurements with $\mathrm{FeSi}_{2}$ up to $675 \mathrm{~K}$ and with $\mathrm{Mg}_{2} \mathrm{Si}$ up to $575 \mathrm{~K}$ have given proof of this.

In summary, we performed several experiments on the applicability of a gallium-based solder with state-of-theart thermoelectrics and different coating materials. The reactivity of the solder in direct contact with coating materials during heat treatment up to $673 \mathrm{~K}$ was investigated and the reaction products of the coating materials with the solder were analyzed using SEM-EDX. We found that tungsten and nickel are promising candidates for 
a protective coating to the Ga-In-Sn solder, whereas only tungsten is long-term stable in contact with Ga-In-Sn. An increase of the maximum temperature of stability was achieved for $\mathrm{Mg}_{2} \mathrm{Si}$ and $\mathrm{FeSi}_{2}$ protected by a nickel coating, leading to a widening of the accessible temperature range for thermoelectric measurements with facial sample contacting.

\section{Conclusion}

The development of contacts is a major part of thermoelectric research as they are crucial for module assembly and material characterization. Contacts must possess low contact resistances to minimize efficiency losses in energy conversion and measurement errors in material characterization. Furthermore, a contact has to be longterm stable, or - in the case of material characterization - at least stable for the duration of the measurement. Chemical differences between the various thermoelectric materials require dedicated contact development for every thermoelectric material and application. Our approach focuses on detachable contacts due to the easy handling and the ability to reuse or change parts of the measurement system or the module after an experiment.

Tungsten is a long-term stable coating material to protect materials from the Ga-In-Sn solder. Due to the observed strong reaction with the solder, titanium can be excluded as a protective coating material. Chromium and nickel also react with the solder, but they are effective protective coatings for short-term applications. In the case of nickel, a highly conductive layer forms that does not cause an increase in contact resistance. Chromium dissolves into the solder and the surface corrodes, but this process is slow compared to the time of a thermoelectric property measurement.

\section{Acknowledgements}

We acknowledge the pleasant partnership to the company aixACCT Systems GmbH, Aachen, Germany in the ZIM project KOMTES (No. KF3139401DF3) funded by the Federal Ministry for Economic Affairs and Energy. Furthermore, the authors would like to thank the Helmholtz Association for financial support. Furthermore, we would really like to thank the reviewers for their work and valuable comments. 
P. Ziolkowski, P. Poinas, J. Leszczynski, G. Karpinski and E. Müller, J. Electron. Mater. 39 (9), 19341943 (2010).

F. P. Brito, L. Figueiredo, L. A. Rocha, A. P. Cruz, L. M. Goncalves, J. Martins and M. J. Hall, J. Electron. Mater. 45 (3), 1711-1729 (2015).

D. Ebling, K. Bartholomé, M. Bartel and M. Jägle, J. Electron. Mater. 39 (9), 1376-1380 (2010).

J. Fan, L. Chen, S. Bai and X. Shi, Mater. Lett. 58 (30), 3876-3878 (2004).

J. García-Cañadas and G. Min, AIP Conference Proceedings 1449 (1), 454-457 (2012).

A. Muto, D. Kraemer, Q. Hao, Z. F. Ren and G. Chen, Rev. Sci. Instrum. 80 (9), 093901 (2009).

H. Iwasaki, T. Yamamoto, H. Kim and G. Nakamoto, J. Electron. Mater. 42 (7), 1840-1845 (2013).

J. Martin, T. Tritt and C. Uher, J. Appl. Phys. 108 (12), 121101 (2010).

R. Amatya, P. M. Mayer and R. J. Ram, Rev. Sci. Instrum. 83 (7), 075107 (2012).

D. Kraemer and G. Chen, Rev. Sci. Instrum. 85 (2), 025108 (2014).

L. I. Anatychuk and V. V. Lysko, J. Electron. Mater. 43 (10), 3863-3869 (2014).

A. Miner and U. Ghoshal, Appl. Phys. Lett. 85 (3), 506-508 (2004).

M. Kun-Quan and L. Jing, J. Phys. D: Appl. Phys. 40 (15), 4722 (2007).

P. Sen and C. J. Kim, IEEE Trans. Ind. Electron. 56 (4), 1314-1330 (2009).

R. C. Chiechi, E. A. Weiss, M. D. Dickey and G. M. Whitesides, Angew. Chem. Int. Ed. 47 (1), $142-$ 144 (2008).

P. Surmann and H. Zeyat, Anal. Bioanal. Chem. 383 (6), 1009-1013 (2005).

N. B. Morley, J. Burris, L. C. Cadwallader and M. D. Nornberg, Rev. Sci. Instrum. 79 (5), 056107 (2008).

L. C. Cadwallader, presented at the Conference: Energy Facility Contractors Group (EFCOG) Safety Analysis Working Group (SAWG) 2003 Annual Meeting, Salt Lake City, UT (US), 06/21/2003-06/27/2003; Other Information: PBD: 7 May 2003, 2003 (unpublished).

F. Barbier and J. Blanc, J. Mater. Res. 14 (03), 737-744 (1999).

V. Y. Prokhorenko, V. V. Roshchupkin, M. A. Pokrasin, S. V. Prokhorenko and V. V. Kotov, High Temp. 38 (6), 954-968 (2000).

H. Kolb, T. Dasgupta, K. Zabrocki, E. Mueller and J. de Boor, Rev. Sci. Instrum. 86 (7), 073901 (2015).

A. Schmitz, C. Schmid, J. de Boor, C. Stiewe and E. Müller, Mater. Today: Proceedings 2 (2), 705-713 (2015).

J. de Boor, C. Compere, T. Dasgupta, C. Stiewe, H. Kolb, A. Schmitz and E. Mueller, J. Mater. Sci. 49 (8), 3196-3204 (2014).

P. Ziolkowski, C. Stiewe, J. de Boor, I. Druschke, K. Zabrocki, F. Edler, S. Haupt, J. König and E. Mueller, J. Electron. Mater. 46 (1), 51-63 (2017).

J. de Boor, C. Stiewe, P. Ziolkowski, T. Dasgupta, G. Karpinski, E. Lenz, F. Edler and E. Mueller, J. Electron. Mater. 42 (7), 1711-1718 (2013).

J. de Boor, C. Gloanec, H. Kolb, R. Sottong, P. Ziolkowski and E. Müller, J. Alloys Compd. 632, 348353 (2015).

T. Sakamoto, Y. Taguchi, T. Kutsuwa, K. Ichimi, S. Kasatani and M. Inada, J. Electron. Mater. 45 (3), 1321-1327 (2015).

D. Zhao, M. Zuo, Z. Wang, X. Teng and H. Geng, Appl. Surf. Sci. 305, 86-92 (2014).

D. E. Newbury and N. W. M. Ritchie, Journal of Materials Science 50 (2), 493-518 (2015).

K. Nogi, T. Kita and X. Q. Yan, Mater. Sci. Eng. A 307 (1-2), 129-133 (2001).

T. Caillat, A. Borshchevsky and J. P. Fleurial, AIP Conference Proceedings 301 (1), 517-520 (1994).

P. W. T. S. Hidnert, Scientific Papers of the Bureau of Standards 20, 483 (1925).

J. S. Przybyszewski, NASA TN D-6184, 1-21 (1971).

T. A. Lobova and T. A. Syrvacheva, SOV Powder Metall 22 (4), 321-323 (1983).

H. Okamoto, J. Phase Equilib. 23 (5), 457-458.

J. L. Murray, Bull. Alloy Phase Diagr. 6 (4), 327-330 (1985).

Figure captions

Figure 1: Sketch of the sample mounting in the sample holder. A liquid metal solder is used to provide contact between the sample and the two chromium-plated copper blocks. For electrical and temperature measurements a thermocouple is placed in a small hole in each of the blocks. Resistive heaters are embedded in a further hole of each block. 
Figure 2: Apparent electrical conductivity of FeSi2 (a), CoSb3 (b) and Mg2Si (c) measured in the CTEM without protective coating on the sample surfaces. Gallium/indium/tin was used as a liquid metal solder. Solid symbols are used for the heating and unfilled symbols for the cooling branch of the measurements. All reference data was measured with a system which does not require a contact development due to the use of pressure contacts in a four-probe inline measurement set-up 25 .

Figure 3: SEM images of bulk samples of the pure coating materials after a temperature treatment of $773 \mathrm{~K}$ for $24 \mathrm{~h}$ in a vacuum oven and in direct contact with the solder. The samples have been cleaned with ethanol before the SEM investigations to remove the liquid solder remains. Titanium is shown in (a), nickel in (b), chromium in (c) and tungsten in (d). A formation of different phases can be observed on the surface of all materials except for tungsten. The composition of the phases is shown in Table I. A two-phase system forms with Ti, a homogeneous layer with small inclusions with $\mathrm{Ni}$ and a crumbly structure with $\mathrm{Cr}$. No reaction layer can be found for tungsten. The thickness of the reaction layers on the bulk samples of the coating materials and the solder vary strongly due to differences in their reactivity and corrosion rates.

Figure 4: Electrical conductivity measured on thermoelectric samples with protective Ni coating compared to uncoated samples. (a) FeSi2 coated by electroplating, (b) $\mathrm{Mg} 2 \mathrm{Si}$ bonded by direct sintering. The four-probe inline reference data were obtained by a system for high temperature measurement of Seebeck-coefficient and electrical conductivity 25 . Solid symbols show the first branch of the measurement when the samples are heated up from point to point, unfilled symbols indicate the following cooling-down branch.

Figure 5: CoSb3 sample with tungsten coating (a) and with double layer titanium/tungsten coating (b). 